\title{
A Research on Dual Fuel Operation on LHR Diesel Engine
}

\author{
Sivakumar Ellappan, Prabhu Kishore, P. Suresh
}

\begin{abstract}
Importance of this investigation is $100 \%$ biodiesel make use as fuel for low heat rejection (LHR) diesel engine. Due to this reason bio-fuels namely, eucalyptus oil and paradise oil were selected and used as dual fuel. Conventional engine hardware parts were coated with lanthana-doped yttriastabilized zirconia (the doping of YSZ coatings with small amount of La2O3) with a thickness of $300 \mu \mathrm{m}$, so as to analyze the operating parameters of paradise oil-eucalyptus oil blends. Tests run were replicated on the conventional diesel engine and outcomes were compared. Test outcomes confirmed that the major intention of this research was attained as engine operating parameters like, brake thermal efficiency, exhaust gas temperature were increase with decrease of fuel consumption. In addition, engine emissions of $\mathrm{HC}, \mathrm{CO}$ and smoke were reduced with exception of NOx for LHR diesel engine than conventional engine.
\end{abstract}

Keywords: Lanthana-doped yttria-stabilized zirconia, paradise oil, Eucalyptus oil, Duel fuel, Emission.

Graphical abstract

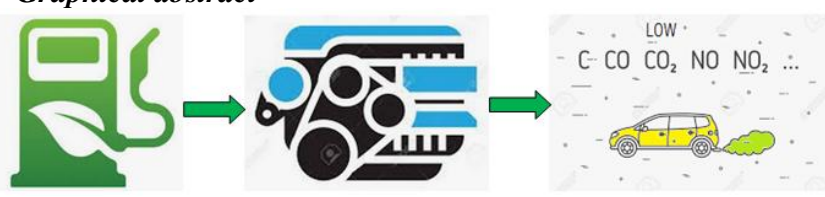

\section{INTRODUCTION}

The reservoirs of petroleum oils are decreasing gradually and developing demand of oils and in addition progressively strict rules and regulations represent a challenge to researchers. Biodiesel is a good substitute for diesel, it is expressed as fatty acid ethyl or methyl ester derived from vegetable oils and moreover, it is renewable, eco-friendly and oxygenated. While a numerous researchers informed, biodiesel may diminish greenhouse gas, encourage rural improvement and develop revenue division, but still some problems are there for utilizing it. Major reason is deficient in knowledge about biodiesel on diesel engine.

Many numbers of researchers have been identified about difficult issues of engine function on straight vegetable oil. Common oppositions to direct utilization of neat vegetable oil in diesel engine relate generally to their high viscosity [1, 2]. Higher viscosity is the root cause of partial atomization, carbon particles on injectors, sticking of piston ring, corrosion, etc. [3, 4]. These issues were overwhelmed by synthetically altering the vegetable oil and mixing it with diesel [5]. Esterifies oils will reduce the emission and improve the performance of the engine. Venkanna and Venkataraman (2015) conducted a test on diesel engine

Revised Manuscript Received on 14 August, 2019.

SivakumarEllappan, Department of Mechanical Engineering, MLR Institute of Technology, Hyderabad 500043, Telangana, India.

Prabhu Kishore, Department of Mechanical Engineering, MLR Institute of Technology, Hyderabad 500043, Telangana, India.

P. Suresh, Department of Mechanical Engineering, St.Martin's Engineering College, Hyderabad 500043, Telangana, India. fuelled by honne oil with diesel. They observed that brake specific fuel consumption (BSFC) in case of $\mathrm{H} 20$ was almost equal to diesel and smokes, $\mathrm{CO}$ were same as to diesel. For all loads, $\mathrm{CO}_{2}$ emission of honne oil is higher than diesel fuel [6]. John PanneerSelvam and Vadivel (2013) have investigated the Waste pork lard blends with diesel in a single cylinder diesel engine. They observed that BSFC was higher than diesel but, slight decreases in BTE. $\mathrm{NO}_{\mathrm{x}}, \mathrm{HC}, \mathrm{CO}$ and smoke were decreased than diesel [7]. Lakshmi NarayanaRao et al., (2007) test a diesel engine using Jatropha methyl ester. They were observed that the ignition delay of JME was lower than diesel owing to inbuilt oxygen of JME. Pressure rise is higher for diesel than JME. $\mathrm{NO}_{\mathrm{x}}$ emissions reduced but $\mathrm{HC}, \mathrm{CO}$, Soot concentration were lower than diesel [8]. HasanSerin and Neslihan Yucel Aka (2014) discussed four cylinder engine fueled by tea seed oil with the addition of diesel at different proportion. Resulted in, increases in specific fuel consumption (SFC) for all blends compared with diesel. $\mathrm{CO}, \mathrm{CO}_{2}$ emission decreased and $\mathrm{NO}_{\mathrm{x}}$ emission was increased with addition of biodiesel in the blend up to $16.86 \%$ [9]. Devan and Mahalakshmi (2009) investigated paradise oil blends with diesel and concluded that BTE of paradise oil was lower than diesel. A notable diminution in $\mathrm{HC}$ and smoke emission were recorded for paradise oil $50 \%$ blends and paradise oil $100 \%$ respectively. Higher $\mathrm{NO}_{\mathrm{x}}$ emission was detected for paradise oil 50\% and paradise oil 100\% [10].

A positive reduction of emission is possible while using biodiesel in diesel engines, but performance point of view, it is suspicion one. So, with the aim of increase the efficiency of diesel engine by insulation of combustion hardware using ceramics coating termed as low heat rejection engine (LHR) with the some drawbacks $[11,12]$. BSFC and emission were decreases because of higher in-cylinder temperature of LHR engine, except $\mathrm{NO}_{\mathrm{x}}$. Significance of biodiesel can be considered, for example, decreased fumes outflow and ability of holding a similar power yield. This present work is for the most part focusing to join the upsides of LHR engine idea and perfect biodiesel. It is found from the survey of literature that the biodiesels are degradable, non-toxic, ecofriendly and renewable. These qualities of biodiesel make us use as a fuel in CI engine. Moreover, it reduces various emissions considerably when compared to that of diesel. However, it has some disadvantages such as slower performance and higher emission of oxides of nitrogen. This might be high pour point, lower volatility, lower heating value, meager oxidation stability and high viscosity. Further, the use of biodiesel is limited to maximum of $30 \%$ with diesel.

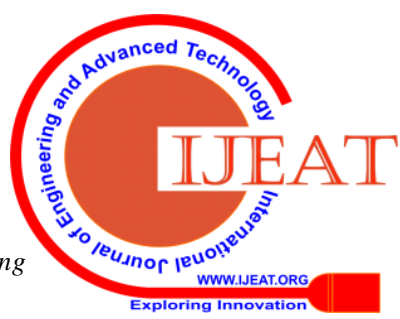


While using beyond $30 \%$, its performance will be reduced drastically and emitting higher amount of $\mathrm{NO}_{\mathrm{x}}$ emission. The biodiesel usage in CI engine can be made in to $100 \%$ and to develop the fuel properties, performance and reduction of emissions, various techniques have been incorporated. Hence, in the present investigation instead of diesel, another biodiesel (primary) having similar properties of diesel blended with secondary biodiesel with different proportions. Even though using another biodiesel in $\mathrm{CI}$ engine will reduce the performance than diesel-fuelled engine, because of its lower energy value. Therefore, present investigation to enhance the thermal efficiency and reduction of emissions, LHR engine is operated with blends of primary and secondary biodiesels.

Experimental works conducted by using eucalyptus oil with paradise oil. The convenience and dependability of vegetable oils in a thermally protected diesel engine coated with lanthana-doped yttria-settled zirconia and conventional engine were investigated. The experimental procedure was repeated with diesel on both engines. The test results were compared between paradise oil blends with eucalyptus oil and diesel for both the engines.

\section{METHODOLOGY \& RESULTS}

The following Table 1 shows the properties of comparison of eucalyptus oil and methyl esters of pongamia (MEPO) with diesel. From the table, the important properties of two biodiesels have similar to diesel, apart from cetane number of eucalyptus oil.

Table 1 Properties of eucalyptus oil, MEPO and diesel

\begin{tabular}{lllll}
\hline Fuel Property & $\begin{array}{l}\text { Eucalyptus } \\
\text { Oil }\end{array}$ & MEPO & $\begin{array}{l}\text { MEPO50- } \\
\text { Eu50 }\end{array}$ & Diesel \\
\hline $\begin{array}{l}\text { Kinematic viscosity } \\
\text { at } 40^{\circ} \mathrm{C}(\mathrm{cst})\end{array}$ & 2.1 & 5.5 & 3.8 & 3 \\
$\begin{array}{l}\text { Calorific value in } \\
\mathrm{kJ} / \mathrm{kg}\end{array}$ & 43,270 & 40,285 & 41,778 & 42,700 \\
Density & 0.8955 & 0.8752 & 0.8852 & 0.84 \\
Cetane Index & 18 & 64 & 41 & 47 \\
$\begin{array}{l}\text { Flash point in }{ }^{\circ} \mathrm{C} \\
\text { Fire point in }{ }^{\circ} \mathrm{C}\end{array}$ & 54 & 141.2 & 102 & 57 \\
\hline
\end{tabular}
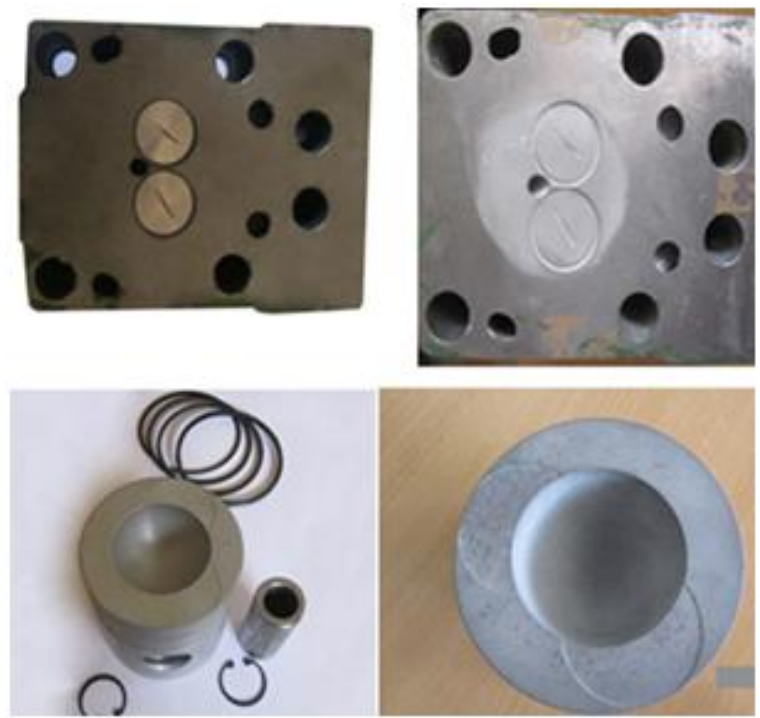

Figure 1 Snap shot of the un-coated combustion parts (left) and coated parts (right)
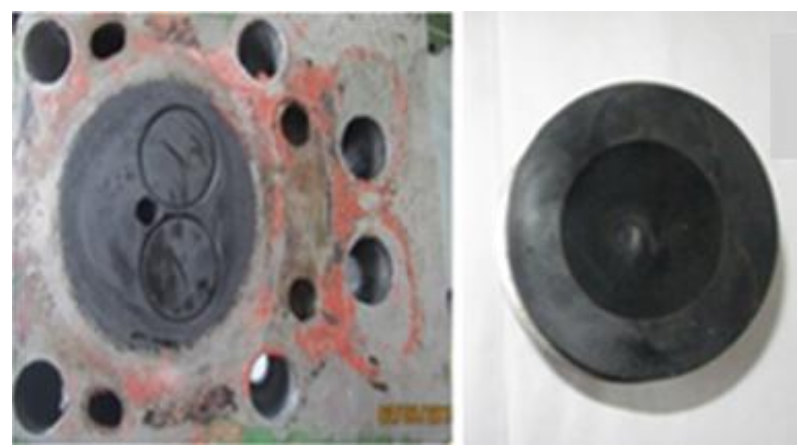

Figure 2 Cylinder head, valves and piston surfaces after 100 hours of engine operation

Note that conventional engine hardware parts were coated with lanthana-doped yttria-stabilized zirconia (the doping of YSZ coatings with small amount of La2O3) with a thickness of $300 \mu \mathrm{m}$ (refer Figure 1 and Figure 2).

\subsection{Experimental installations}

Tests conducted in a DI diesel engine. Layout of test rig and other components are in Figure 3 and technical data of the test rig is tabulated in Table 2.

Table 2 Technical data of the test rig

\begin{tabular}{cc}
\hline Details & Specification \\
\hline Make & Kirloskar Oil Engines Limited, Model \\
SV1 & S stroke, vertical, Single cylinder, \\
Wype & $87.5 \times 110(\mathrm{~mm})$ \\
Bore and stroke & $17.5: 1$ \\
Compression ratio & $8 \mathrm{HP}(5.9 \mathrm{~kW})$ \\
Rated output & $1800 \mathrm{rpm}$ \\
Speed & $200 \mathrm{bar}$ \\
Injection pressure & Eddy current dynamometer \\
Loading &
\end{tabular}

Table $3 \%$ errors in the measured data's

\begin{tabular}{cc}
\hline Parameters & $\%$ Error \\
\hline $\mathrm{O}_{2}$ & 1.054 \\
$\mathrm{NOx}$ & 0.941 \\
$\mathrm{HC}$ & 1.031 \\
$\mathrm{CO}$ & 0.092 \\
Temperature & $4^{\circ} \mathrm{C}$ \\
\hline
\end{tabular}




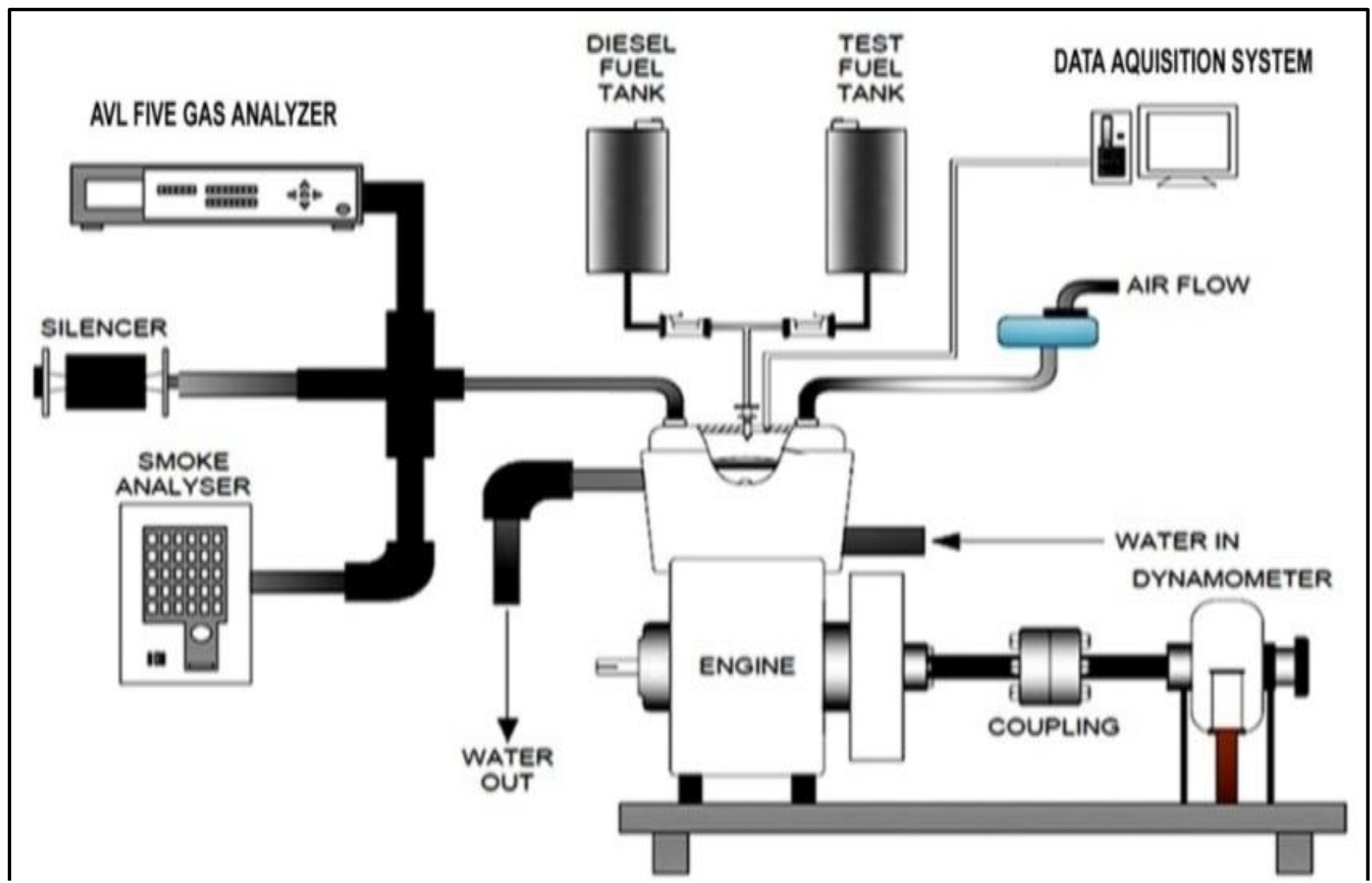

Figure 3 Experimental Setup

This study evaluates the operating characteristics of LHR engine fuelled by optimal blend of MEPO50-Eu50 is evaluated. The proportion of 50\% MEPO with 50\% eucalyptus oil is selected as a best blend from various biodiesel blends based on the Combinatorial Mathematical Based Approach. The graphs are plotted BSFC, BTE, and
EGT, emission of $\mathrm{CO}$, hydrocarbon, $\mathrm{NO}_{\mathrm{x}}$ and smoke with the load.

\section{BRAKE SPECIFIC FUEL ENERGY CONSUMPTION (BSEC)}

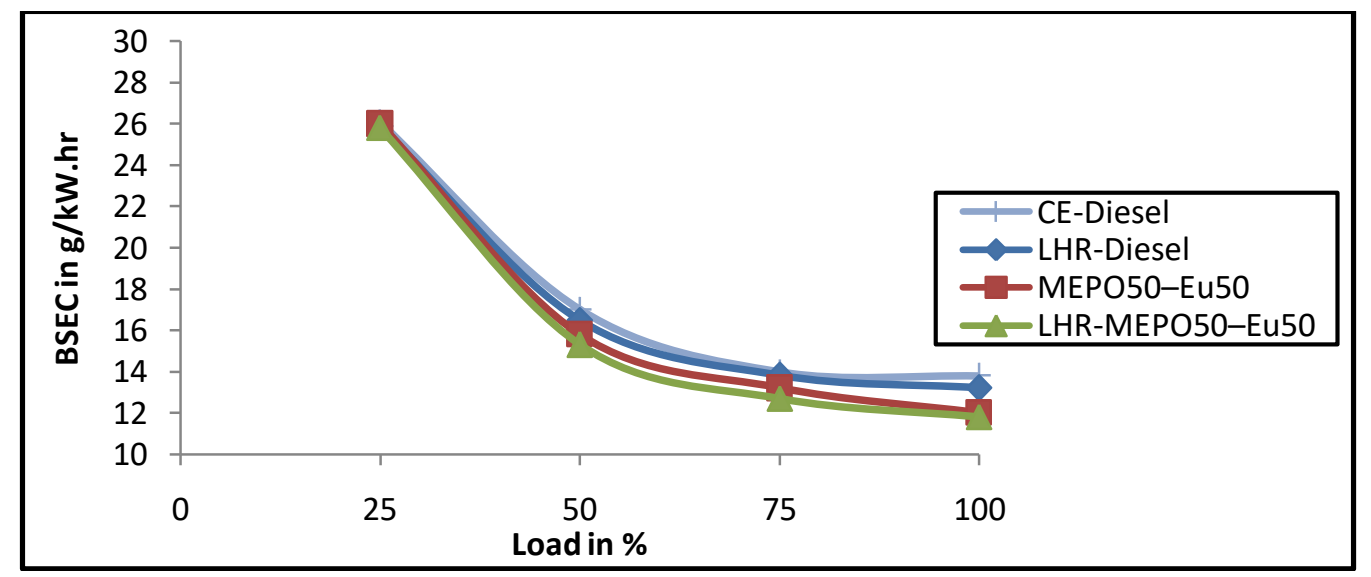

Fig.4 Load Vs Brake specific energy consumption

The BSFC of methyl ester of paradise oil with eucalyptus oil and diesel on coated and conventional diesel engines is shown in Fig.4. It is clear from the graph that the BSEC reduces with raises of load on all fuels in LHR engine. It is owing to the higher combustion temperature caused by coating reduced the viscosity and density of the fuels. It is also noticed that BSEC for methyl ester of paradise oil and eucalyptus oil blend is $11.6 \mathrm{MJ} / \mathrm{kW}$-hr, which is $0.4 \mathrm{MJ} / \mathrm{kW}$ $\mathrm{hr}$ inferior than that of diesel and this may be due to the mass flow of the blend and it is high as of diesel. Since paradise oil and eucalyptus oil blend has low calorific value.

\subsection{Brake Thermal Efficiency (BTE)}

Published By:

Blue Eyes Intelligence Engineering \& Sciences Publication

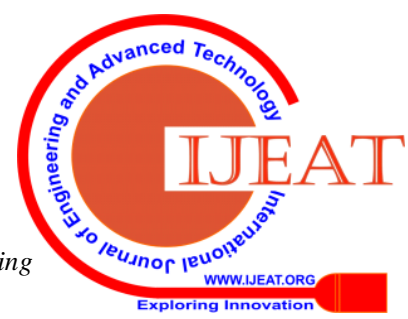




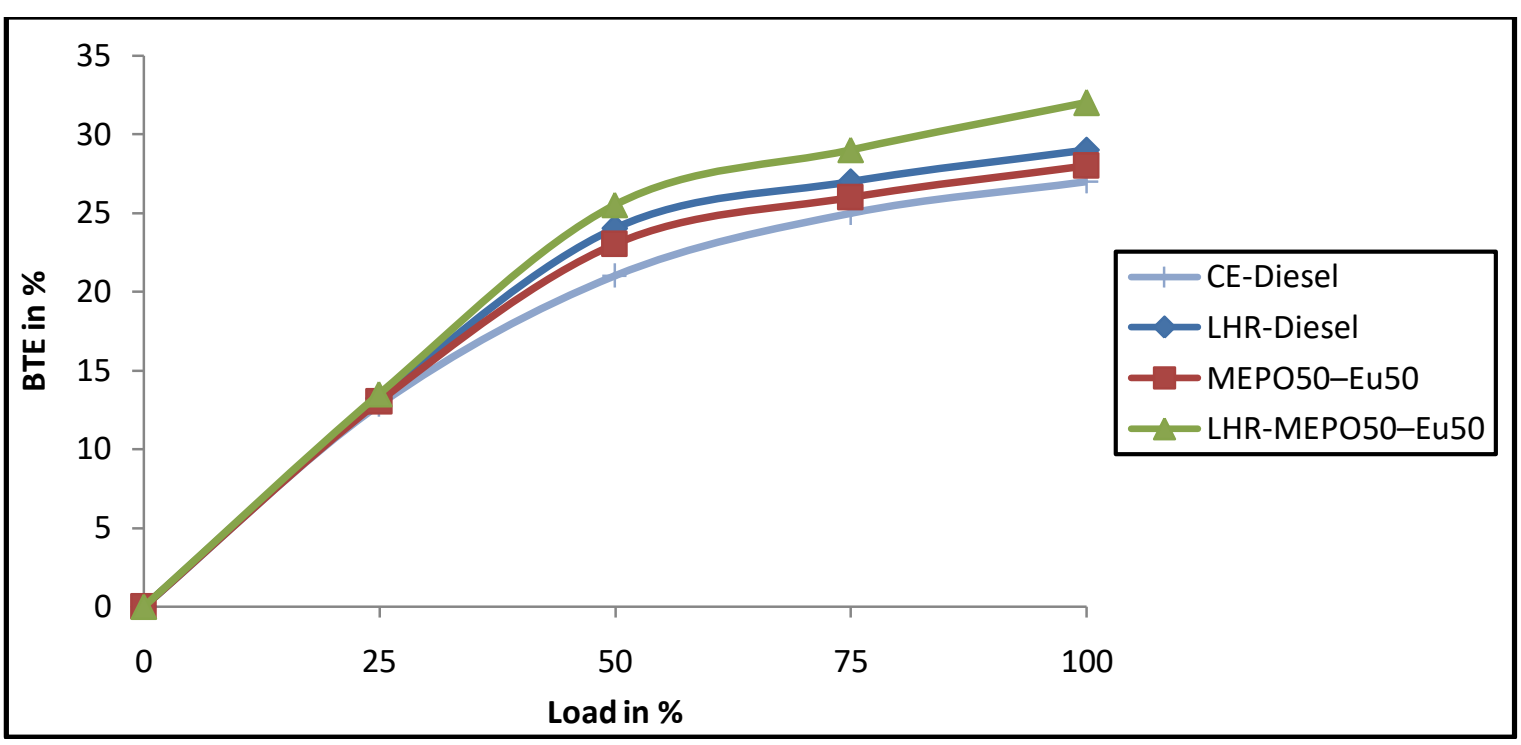

Fig.5 Load Vs brake thermal efficiency

Thermal efficiency is the true indication of the efficiency with which the chemical energy input in the form of fuel is converted into useful work. Improvement in engine thermal efficiency by reduction of in-cylinder heat transfer is the key objective of LHR engine research. The brake thermal efficiency of methyl ester of paradise oil and eucalyptus oil biodiesel blends and diesel for coated and conventional diesel engine is shown in Fig.5. It is seen from the graph that the BTE increases with increase of brake power for all the fuels. This is due to higher temperature attained by the engine at higher loads. It is noticed that the BTE for MEPO50-Eu50 blend in LHR engine is $32.5 \%$ and it is $2.5 \%$ higher than that of diesel. This is because of heat transferred via combustion chamber parts are decreased due to the ceramic coating and resulting higher in-cylinder gas and wall temperature. Hence, combustion is improved and thereby contributed to increase the brake thermal efficiency.

Thermal efficiency is the genuine sign of the proficiency with which the compound vitality contribution to the type of fuel is changed over into helpful work. Improvement in thermal efficiency by decrease of in-chamber heat exchange is the key goal of LHR engine research. The brake thermal effectiveness of paradise oil and eucalyptus oil biodiesel mixes and diesel for covered and ordinary diesel engine is appeared in Fig.5. It is seen from the diagram that the BTE increments with increment of brake control for every one of the powers. This is because of higher temperature achieved by the engine at higher loads. It is seen that the BTE for MEPO50-Eu50 mix in LHR engine is $32.5 \%$ and it is $2.5 \%$ higher than that of diesel. This is a direct result of warmth exchanged by means of burning chamber parts are diminished because of the artistic covering and coming about higher in-barrel gas and divider temperature. Henceforth, burning is improved and in this way added to build the brake warm effectiveness.

\subsection{Carbon Monoxide Emission (CO)}

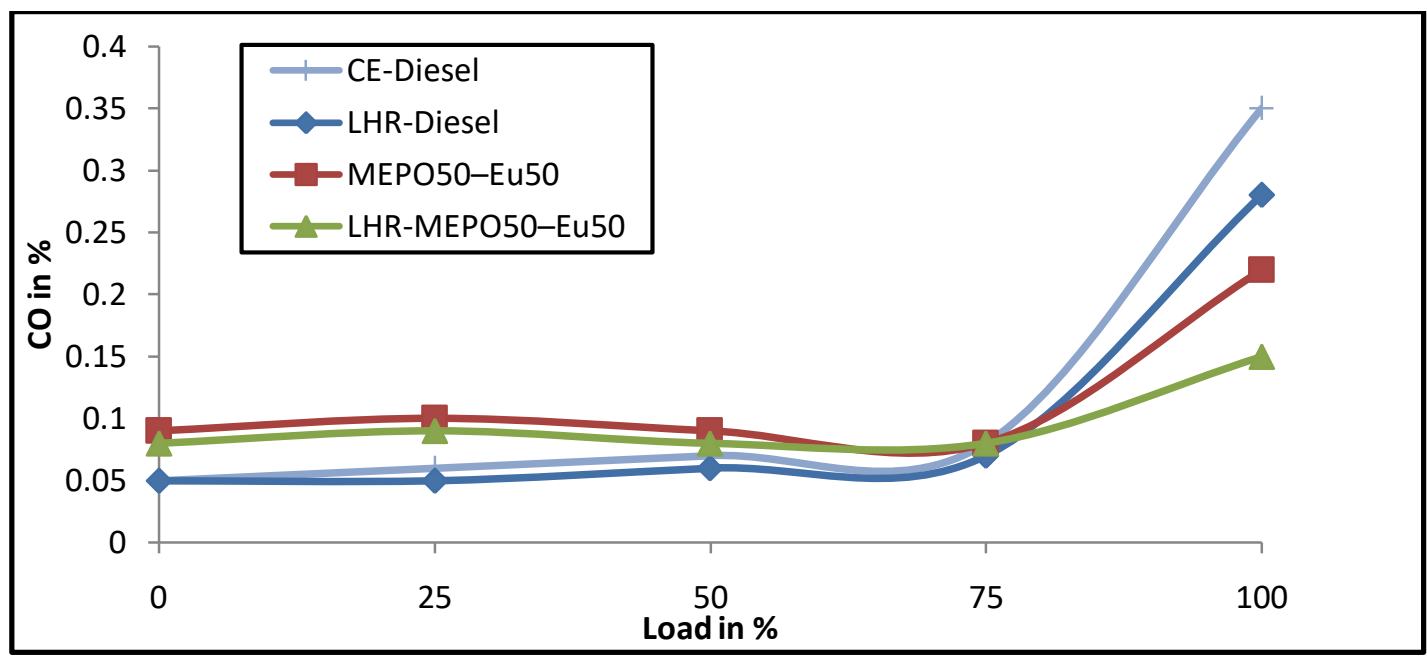

Fig.6 Variation of carbon monoxide emission with load 
The carbon monoxide of paradise oil with eucalyptus oil and diesel for coated and conventional diesel engine is shown in Fig.6. Generally $\mathrm{CO}$ is the effect of incomplete combustion and be deficient in oxygen. From graph at lower and medium loads, $\mathrm{CO}$ emission of all blends in LHR engine is not much variation than diesel fuelled conventional engine. However at higher load, $\mathrm{CO}$ emission for blends decreases significantly than diesel. It is due to higher temperature of gas and combustion chamber walls. It leads to decrease the initial making of CO. On contrary, at high temperature accelerate the oxidation of $\mathrm{CO}$ during diffusion combustion. It is also found that the $\mathrm{CO}$ emission of MEPO50-Eu50 blend is $0.21 \%$ for LHR engine. It is $13 \%$ inferior to that of diesel. This is owing to the improvement of oxygen present in eucalyptus oil and paradise oil.

\subsection{Exhaust Gas Temperature}

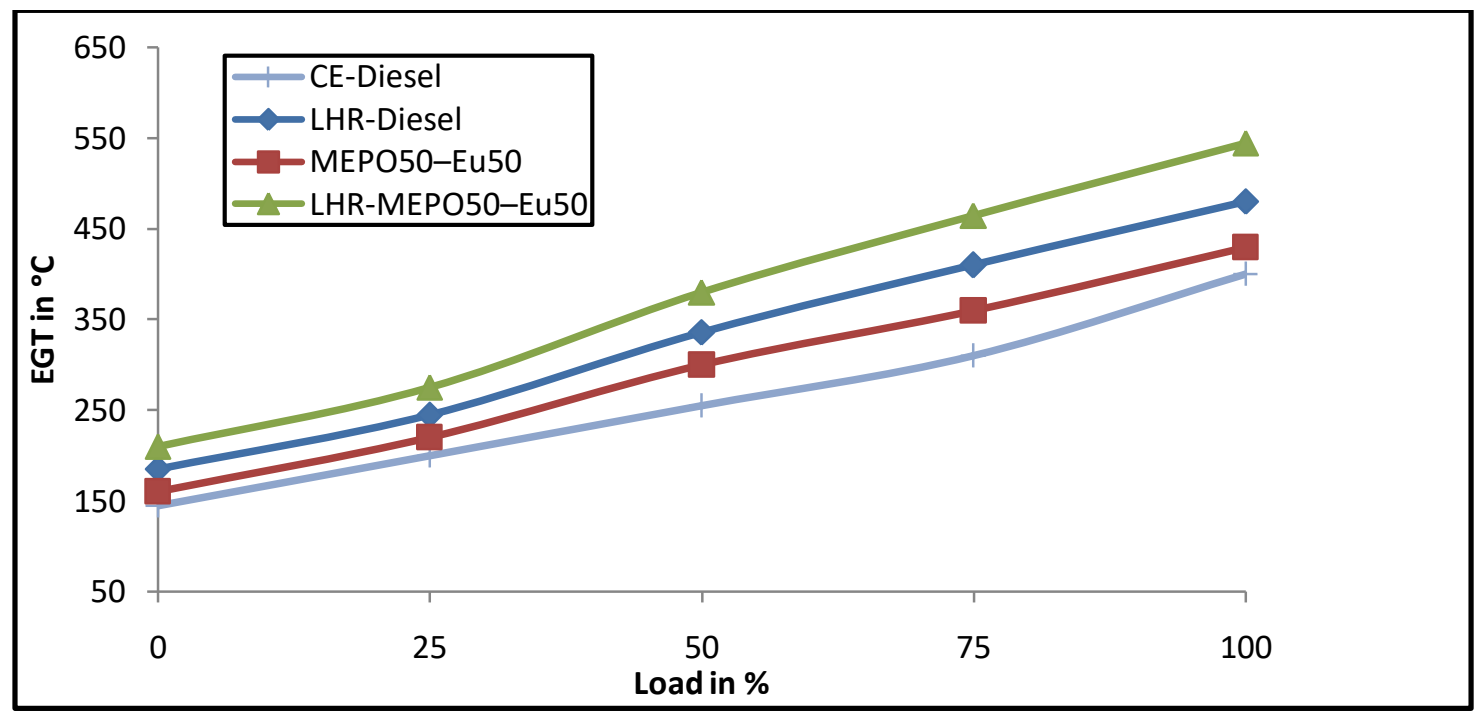

Fig.6 Load Vs EGT

The changes of Exhaust gas temperature of methyl ester of paradise oil with eucalyptus oil and diesel for covered and customary diesel engine is appeared in Fig.6. All in all, the fumes gas temperature was expanded with increment in engine load for all the test powers. This is on the grounds that the measure of fuel per unit time increments as the engine loads increments, and thus more warmth vitality is created. Accordingly, fumes gas temperature increments. It is surmised that the fumes gas temperature of the MEPO50-
Eu50 in LHR engine is higher than that of customary engine. This might be because of more warmth is exchanged to the fumes gas, since the burning parts are given fired covering. At higher loads, EGT of MEPO50-Eu50 mix is $410^{\circ} \mathrm{C}$, which is $15^{\circ} \mathrm{C}$ higher than that of diesel, in view of its higher calorific value, lower density and ceramic covering.

\subsection{Hydrocarbon Emission (HC)}

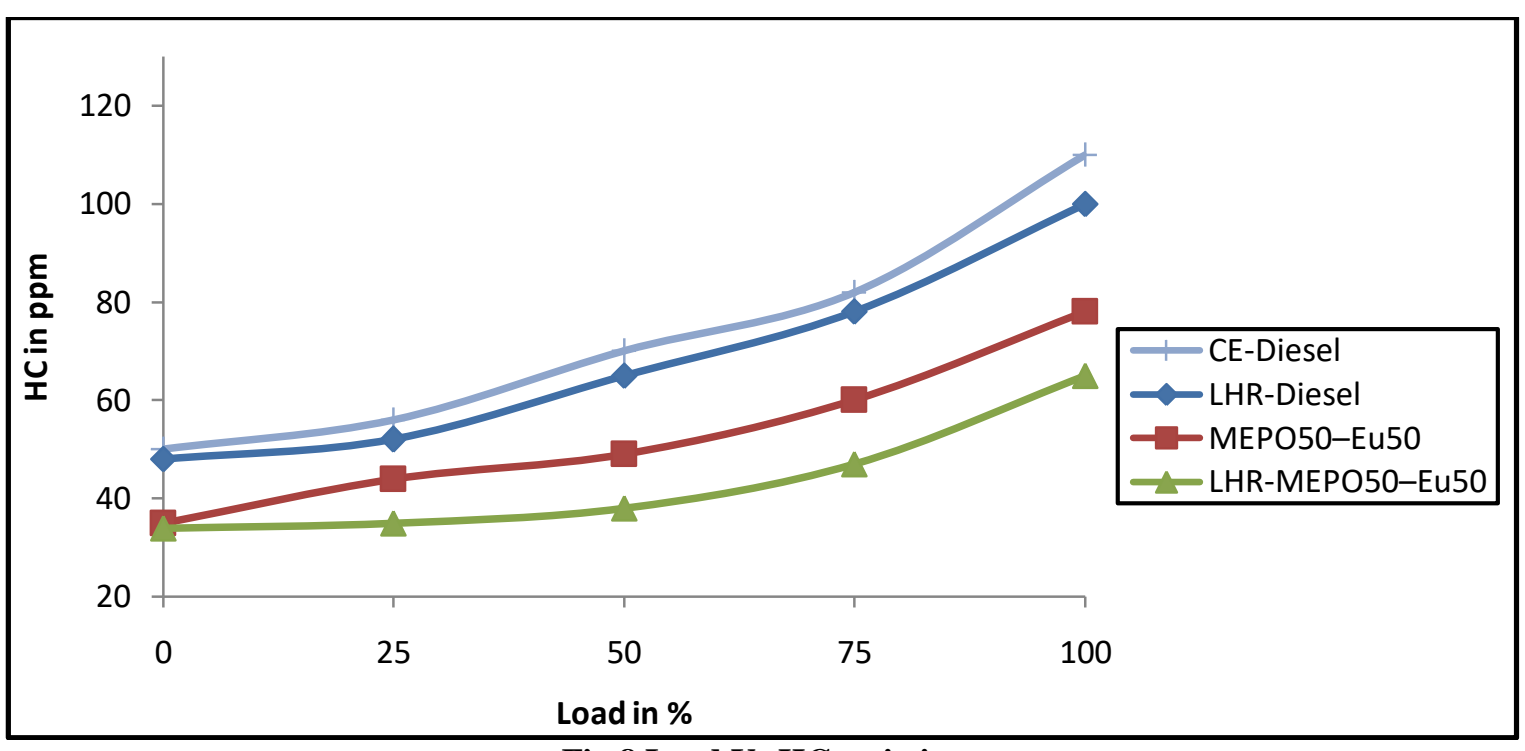

Fig.8 Load Vs HC emission 


\section{A RESEARCH ON DUAL FUEL OPERATION ON LHR DIESEL ENGINE}

The hydrocarbon discharge of methyl ester of heaven oil with eucalyptus oil and diesel for covered and ordinary diesel engine is appeared in Fig.8. HC outflow was significantly diminished when utilizing vegetable oil mixes fuel in diesel engine. It is gathered that the $\mathrm{HC}$ emanation of LHR engine for MEPO50-Eu50 is second rate compared to that of regular engine. This is because of the decrease of warmth misfortunes to the cooling framework and diminished extinguishing separation and expanded lean combustibility limit. Further, higher temperature of the ignition chamber divider and in-barrel gas improves the oxidation response, result in better burning. It has been surmised that MEPO50-Eu50 mix indicated $38 \mathrm{ppm}$ of $\mathrm{HC}$ emanation that is $17 \mathrm{ppm}$ sub-par compared to that of diesel. It is because of the lower refining temperature of eucalyptus oil balances the poor instability attributes of MEPO. It improves the dissipation rate and permits better blending of fuel with air along these lines upgrading burning and decreasing the $\mathrm{HC}$ discharge.

\subsection{NOx Emission}

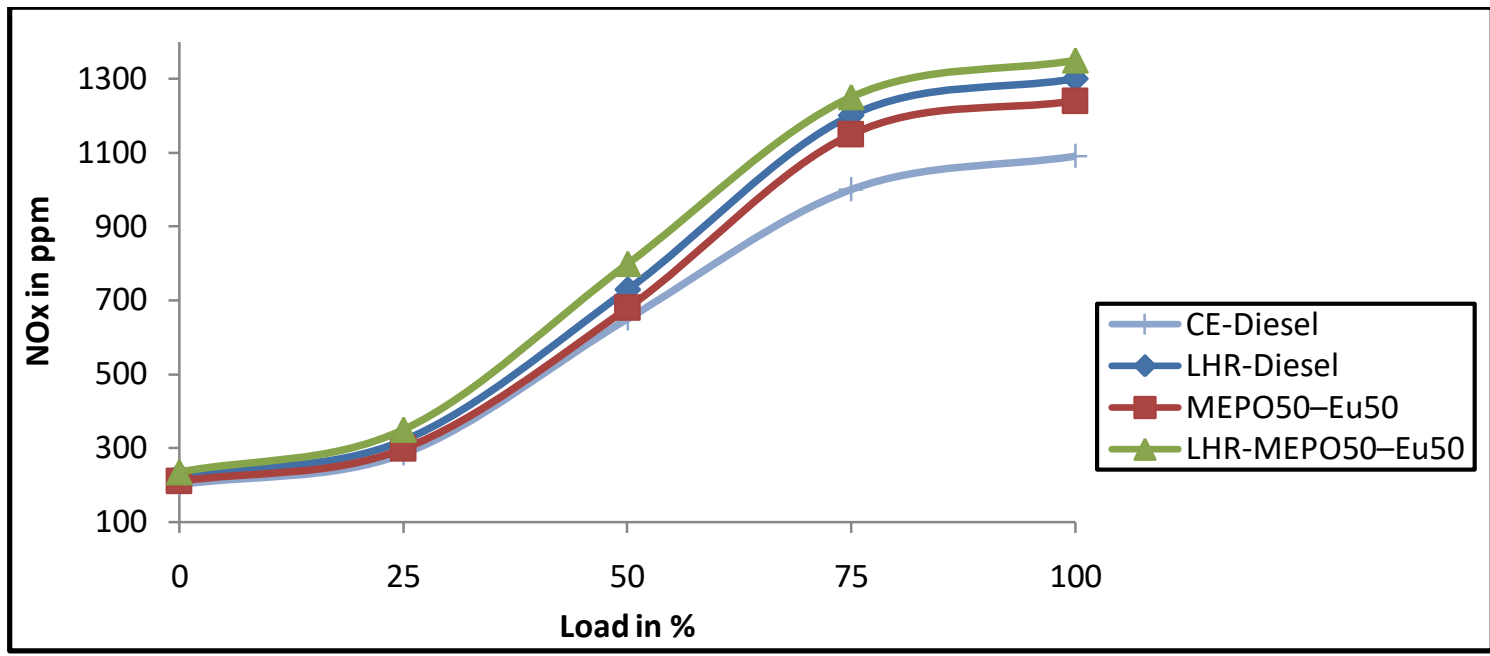

Fig.9 Load VsNOx emission

The variety of oxides of nitrogen of methyl ester of paradise oil with eucalyptus oil and diesel for covered and ordinary diesel engine is appeared in Fig.9. At the point when vegetable based powers are utilized in the test engine, the higher oxygen content is considered to improve burning and results in higher ignition temperature and in this manner higher NOx outflow too. The arrangement of NOx emanation is influenced by two primary critical components. The first is in-barrel ignition temperature is roughly higher than $1600^{\circ} \mathrm{C}$, nitrogen atoms start to partake in the response and accordingly produce NOx. The second one is the response time is sufficient for the above explanations. It is seen from the assume that the NOx emanation increments directly for burdens. It is induced that at higher burdens, the general fuel- air proportion increments bringing about an expansion in the normal gas temperature in the burning chamber and consequently NOx arrangement. It is seen that the NOx emanation for MEPO50-Eu50 mix in LHR engine is as diesel engine. Higher ignition temperature and longer burning span in nearness of protection are reason for NOx. MEPO50-Eu50 indicated $970 \mathrm{ppm}$ of NOx outflow at full load. It is $18 \%$ high as diesel on account of more oxygen present in the biodiesels mix.

\subsection{Smoke}

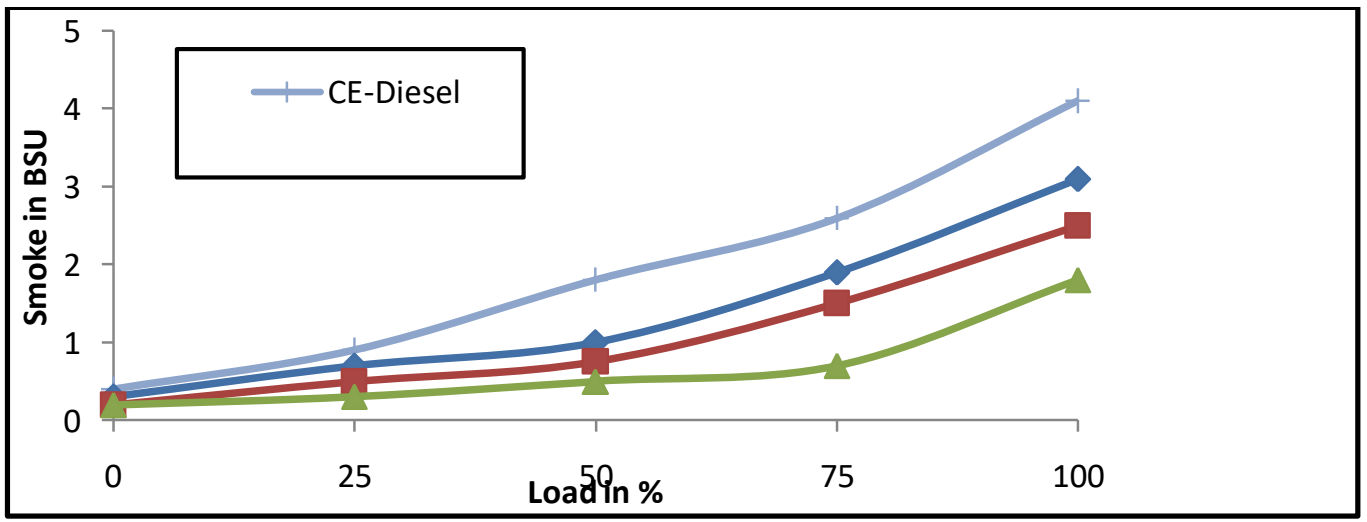

Fig.10 Load Vs Smoke emission 
The smoke of methyl ester of paradise oil with eucalyptus oil and diesel for coated and conventional diesel engine is plotted in Fig.10. From the figure, smoke emission from LHR engine of all fuels is inferior than that of diesel fuelled conventional engine. This is owing to higher in-cylinder gas and wall temperature than conventional engine. Another reason is the attendance of oxygen in the eucalyptus oil improved diffusive combustion phase and thereby leads to short diffusive combustion duration. Hence, a significant smoke emission reduction is inferred for MEPO50-Eu50 blend. The smoke emission of MEPO50-Eu50 blend is $43 \mathrm{HSU}$, which is $11 \mathrm{HSU}$ low as diesel. It is owing to low viscosity and high energy content of MEPO and eucalyptus oil blend, which improves the atomization and addition of the fuel and thereby reduces the smoke.

\subsection{Peak cylinder pressure}

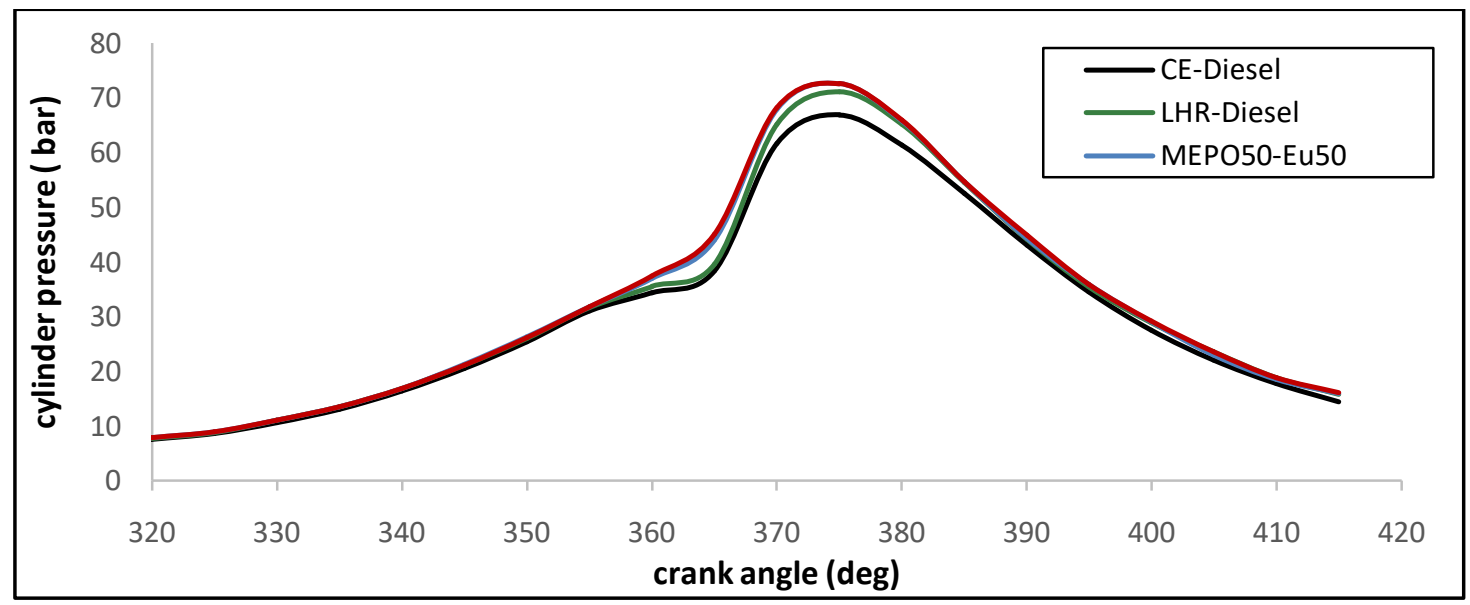

Fig.11 Crank angle Vs cylinder pressure

Figure 11 shows the changes of cylinder peak pressure with crank angle for methyl ester of paradise oil with eucalyptus oil and diesel for coated and conventional diesel engine. From figure, the combustion starts prior for biodiesels blend than diesel. It is owing to low cetane index and high volatility of eucalyptus oil in the blend. Since, biodiesel blends have higher bulk modulus and higher density. It is observed that cylinder pressure increases for LHR engine compared to that of conventional engine. This is as a result of the shorter ignition delay and superior injection timing of biodiesels blend.

\subsection{Heat release rate (HRR)}

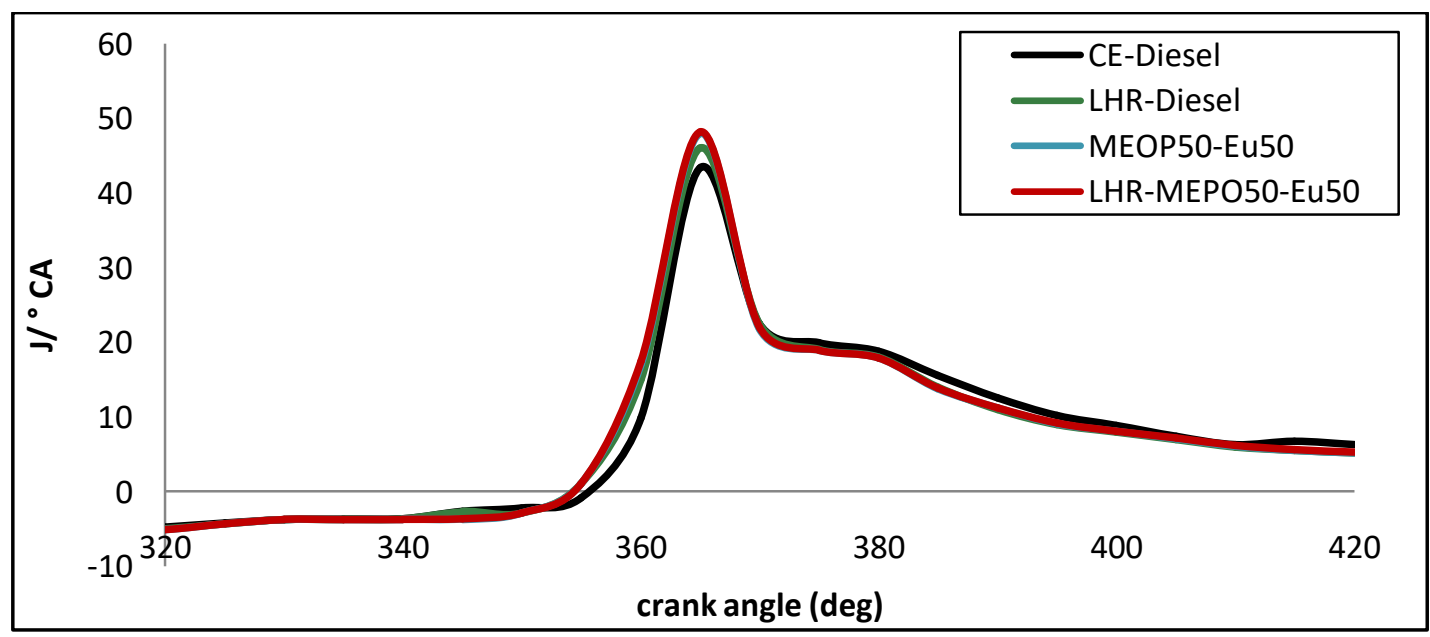

Fig.12 Crank angle Vs HRR

The effects of HRR with crank angle for paradise oil with eucalyptus oil and diesel for coated and conventional diesel engine is indicated in the figure 12. It is from the figure that at beginning of combustion HRR is lower for all fuels owing to vaporisation of the fuel during the ignition delay. However, after ignition delay the combustion is initiated and higher heat release rate is inferred for all fuels. It is also noticed that for LHR engine, MEPO50-Eu50 blend shows higher heat release rate and this is as a result of the higher heating value and lower viscosity of the methyl ester of paradise oil and eucalyptus oil blend. Insulated ceramic coating also improves the HRR than conventional engine. 


\section{CONCLUSIONS}

The performance, emission and combustion characteristics of a single cylinder, four-stroke, DI, thermal barrier coated diesel engine using paradise oil and eucalyptus oil were studied and the test results are given below.

1. Paradise oil and eucalyptus oil can be utilized as a fuel for ordinary and LHR diesel engine.

2. High cetane estimation of paradise oil could make up for the diminished cetane esteem brought about by the eucalyptus oil in the mix.

3. Reduced density and expanded unpredictability are the advantages of this mix.

4. The explicit fuel utilization diminishes for MEPO50-Eu50 mix for covered engine contrasted with that of ordinary diesel engine.

5. Thermal obstruction covering alongside MEPO50Eu50 demonstrated improved execution and diminished outflows at all heaps. It was discovered that $\mathrm{CO}, \mathrm{HC}$ and smoke were diminished fundamentally, while NOx expanded somewhat, when contrasted with that of diesel in both covered and regular diesel engine.

6. Taking these certainties into record, a mix of MEPO50-Eu50 can be utilized as an option reasonable fuel in LHR-DI diesel engine.

\section{REFERENCES}

1. R.O. Dunn, Low-temperature flow properties of vegetable oil/cosolvent blend diesel fuels, J.Am. Oil Chem. Soc. 79 (2002) 709-715.

2. L.C. Meher, D. VidyaSagar, S.N. Naik, Technical aspects of biodiesel production by Transesterification a review, Renew. Sustainable Energy Rev. 10 (2006) 248-268.

3. A. Murugesan, C. Umarani, R. Subramanian, N. Nedunchezhian, Bio-diesel as an alternative fuel for diesel engines $\neg$ - a review, Renew. Sustainable Energy Rev. 13 (2009) 653-662.

4. F.Ma,M.A.Hanna, Biodiesel production-a review, Bioresour. Technol. 70 (1999) 1-15.

5. R. Senthil, E. Sivakumar, R. Silambarasan, Performance and emission characteristics of a low heat rejection engine using Nerium biodiesel and its blends, International Journal of Ambient Energy ISSN: 0143 0750, (2015), 38:2, 186-192.

6. Bhattacharyya S, Reddy CS. vegetable oils as fuels for internal combustion engines: a review. Silsoc Res Inst (1994), 57:157-66.

7. B. K. Venkanna \& C. Venkataraman Reddy, Performance, Emission, and Combustion Characteristics of a Diesel Engine Running on Blends of Honne Oil and Diesel Fuel, International Journal of Green Energy, 2015, 12:7, 728-736.

8. D. John PanneerSelvam\&K.Vadivel, An Experimental Investigation on Performance, Emission, and Combustion Characteristics of a Diesel Engine Fueled with Methyl Esters of Waste Pork Lard and Diesel Blends, International Journal of Green Energy, 2013, 10:9, 908-923.

9. G. Lakshmi NarayanaRao, B. DurgaPrasad, S. Sampath\& K. Rajagopal Combustion Analysis of Diesel Engine Fueled with Jatropha Oil Methyl Ester - Diesel Blends, International Journal of Green Energy, 2007, 4:6, 645658.

10. HasanSerin\&NeslihanYucelAkar The Performance and Emissions of a Diesel Engine Fueled with Tea Seed
(Camellia sinensis) Oil Biodiesel-Diesel Fuel Blends, International Journal of Green Energy, 2014,11:3, 292301

11. P.K. Devan, N.V.Mahalakshmi, Utilization of unattended methyl ester of paradise oil as fuel in diesel engine,Fuel, 2009, 88, 1828-1833

12. P. Tamilporai, N.Baluswamy, Simulation and analysis of heat transfer in low heat rejection direct injection diesel engines using a two zone model, in: 3rd Asian e Pacific International Symposium on Combustion and Energy Utilization.

13. S. Jaichandar, P. Tamilporai, Low heat rejection engines - an overview, 2003-01-0405.

14. P.K. Devan, N.V.Mahalakshmi, A study of the performance, emission and combustion characteristics of a compression ignition engine using methyl ester of paradise oil-eucalyptus oil blends,Applied Energy, 2009, 86,675-680.

15. M. Matsumoto, H. Takayama, D. Yokoe, et al., Scripta Mater.54, 2006, 2035.

16. M. Matsumoto, T. Kato, N. Yamaguchi, et al., Surf.Coat.Technol. 203, 2009, 2835.

17. Y. Liu, Y.F. Gao, S.Y. Tao, et al., J. Therm. Spray.Technol. 17, 2008, 603.

18. Y. Liu, Y.F. Gao, S.Y. Tao, et al., Surf. Coat.Technol. 203, 2009, 1014.

19. Venkata Rao, R.: Decision making in the manufacturing environment using graph theory and fuzzy multiple attribute decision making methods. Vol. 2. Springer. Newyork (2012).

20. Dinesh Singh., Venkata Rao. R.: A hybrid multiple attribute decision making method for solving problems of industrial environment. International journal of industrial engineering computations. 2, 631-644. (2011).

21. Saaty, T.L.The analytic hierarchy process. Mc Graw Hill. Newyork (1980).

22. Venkata Rao, R.: Decision making in the manufacturing environment using graph theory and fuzzy multiple attribute decision making methods. Vol. 1, Springer, Newyork (2007). 